\title{
Documentos
}

\section{0 anos da pós-graduação em educação no Brasil: produção do conhecimento, poderes e práticas*}

\author{
Betania Leite Ramalho \\ Presidente da Associação Nacional de Pós-Graduação e Pesquisas em Educação (ANPEd)
}

Neste momento de reencontro e congraçamento acadêmico e pessoal, em nome da Diretoria da ANPEd e em meu próprio expresso nossa cordial saudação ao conjunto dos associados que constroem e mantêm nossa importante e reconhecida Associação, bem como às autoridades e aos visitantes.

Aproveito o momento para estender nossos agradecimentos ao CNPq, à CAPES, FINEP, FAPESP, FAPERJ, FAPEMIG e ao MEC/INEP/SECAD pelo apoio e suporte financeiro para a realização desta reunião anual. E um especial agradecimento à prefeitura municipal e à rede hoteleira de Caxambu, às autoridades aqui presentes ou representadas.

Com satisfação, expressamos nossa alegria pela presença de todos. Sintam-se recepcionados e acolhidos nesta $28^{\mathrm{a}}$ Reunião Anual.

Há 40 anos, era publicado o parecer $n^{\circ} 977$ do Conselho Federal de Educação, conhecido como Pa-

${ }^{*}$ Discurso pronunciado na abertura da $28^{\mathrm{a}}$ Reunião Anual da ANPEd, realizada em Caxambu (MG), de 16 a 19 de outubro de 2005 . recer Sucupira, que representa o marco legal e inaugural da pós-graduação stricto sensu no país. A partir desse marco regulatório, foi criado o primeiro curso de pós-graduação em educação no Brasil, na Pontifícia Universidade Católica do Rio de Janeiro, iniciado em 1966. Desde então, iniciou-se um longo processo de instalação e regulamentação de cursos e programas - processo contraditório, de avanços e recuos, de aprendizagens para a construção de uma cultura acadêmica que possibilitou que chegássemos à situação na qual nos encontramos hoje.

E quando refletimos sobre essa história, algumas questões que integram o nosso cotidiano de pesquisadores reaparecem com maior intensidade: para quem pesquisamos? Sobre o que e em que condições e com que recursos pesquisamos? Qual o destino de nossas investigações? Os processos e os resultados das nossas pesquisas estão interferindo na construção de uma sociedade mais igualitária?

Essas questões são centrais para todos os que fazem pesquisa educacional, e certamente continuarão a desafiar aqueles que nos sucederão. Nesta $28^{\mathrm{a}}$ Reunião Anual essas questões devem ser reiteradas, en- 
caminhamentos devem ser feitos em toda a programação, e deverão repercutir nos diferentes espaços e instâncias de nossa associação.

Alguns colegas aqui presentes, ao lado de outros tantos que não estão compartilhando conosco este momento, viveram o nascedouro e a expansão da pósgraduação em educação no país. Muitos contribuíram para a construção e desenvolvimento da pós-graduação, cujo projeto ocorre no contexto de modernização conservadora, capitaneada pelo regime militar, cujas metas, definidas nos planos de desenvolvimento nacional implantados no pós-1964, apontavam para a formação de recursos humanos qualificados para todos os níveis de ensino, para a preparação de pesquisadores e para a capacitação de profissionais. Embora esse contexto tenha determinado os aspectos básicos do funcionamento da pós-graduação em educação, sua maturidade foi sendo gestada e redefinida nas lutas pela democratização e justiça social do país.

Nesses 40 anos de pós-graduação stricto sensu, adotamos como princípio norteador avançar na compreensão do que, do como e do para quem ensinamos, enquanto estamos consolidando o paradigma da formação de educadores-pesquisadores comprometidos com a transformação social.

Por sua vez, nos 28 anos de existência da ANPEd muitos percalços foram enfrentados e superados até alcançarmos um razoável patamar de institucionalização da pesquisa como componente fundamental para a formação de quadros de alto nível na educação. No entanto, apesar de todos os esforços, a estratificação social continua impedindo que a pós-graduação ofereça uma contribuição mais efetiva e marcante para a construção de um projeto nacional de educação básica e superior com qualidade e oportunidades para todos. Não podemos deixar de ressaltar, todavia, que os temas da democratização, da inclusão e da diversidade, entre outros, já integram a agenda de alguns setores do governo. Esses temas já vinham sendo privilegiados nos grupos de trabalho e de estudo da ANPEd, e passam a ganhar a perspectiva de políticas públicas.

A pós-graduação em educação não pode, em hipótese alguma, colocar-se à margem do sistema educacional. A ANPEd, assumindo seu papel de agluti- nadora e representante dos programas de pós-graduação em educação e dos pesquisadores a ela associados, vem reafirmando esta posição ao longo dos anos e, mais recentemente, quando se posiciona em relação aos pressupostos que orientam a formulação do V Plano Nacional de Pós-Graduação, que anuncia “o sistema nacional de pós-graduação, enquanto eixo estratégico do desenvolvimento científico, cultural, tecnológico e social do país, deve procurar atender às necessidades nacionais e regionais e continuar contando com políticas públicas que o façam crescer com qualidade e relevância". ${ }^{1}$

Em que pese os obstáculos apontados, há conquistas a celebrar com o coletivo dos associados, principalmente:

- A elevação das reuniões anuais da ANPEd à categoria de evento internacional, pela Comissão de Avaliação de Periódicos e Eventos da CAPES, reconhecimento da relevância desse evento para a socialização do conhecimento produzido na área da educação.

- A inclusão da Revista Brasileira de Educação na coleção SciELO, garantindo-lhe maior visibilidade e possibilidade de acesso nacional e internacional.

- A expressiva resposta à campanha de filiação encetada pela Diretoria, nesses dois anos de gestão.

- O reforço do caráter institucional da ANPEd, via implantação do Sistema de Gerenciamento Acadêmico, Administrativo e Financeiro, que disciplina e otimiza o fluxo das suas diferentes atividades, com destaque para o banco de dados dos associados.

- A institucionalização de ações conjuntas da ANPEd com o MEC, por intermédio da SECAD e do INEP, visando interesses mútuos.

${ }^{1}$ CAPES, Plano Nacional de Pós-Graduação, 2005-2010, Disponível em: <http://www.capes.gov.br/capes/portal/conteudo/ PNPG_2005_2010.pdf>. Acesso em: 15 out. 2005.

Revista Brasileira de Educação $\quad$ v. 11 n. 31 jan./abr. 2006 
- A parceria com a Fundação Ford e a Ação Educativa para realização do IV Concurso Negro e Educação.

Permanecem, contudo, aspectos que nos desafiam como educadores e pesquisadores engajados, entre eles:

- É forçoso questionar os riscos do predomínio da perspectiva produtivista que perpassa todas as áreas, na avaliação da CAPES, em função da qual as de ciências humanas e sociais têm sido sistematicamente prejudicadas. Muito ainda há a ser conquistado no sentido de sermos tratados de forma igual, por sermos pesquisadores, e de forma diferente, por trabalharmos com pessoas, envolvendo-nos em processos de formação humana, e não na fabricação de produtos.

- Precisamos continuar lutando para corrigir as disparidades regionais! É inadmissível convivermos com situações como a da existência de apenas onze programas de pós-graduação stricto sensu em educação na região Nordeste, dez na região Centro-Oeste e três na região Norte. Frente a estes dados, podemos falar em federação?

- A desvalorização dos pesquisadores em educação, submetidos a condições de trabalho e de carreira inadequadas, desestimula a atração e a permanência de quadros de elevado potencial intelectual e acadêmico, configurando perda da centralidade e da relevância da educação como política pública. Lembrando Mariano Fernandez Enguita: desafortunadamente, hoje, o oráculo da pedagogia é a economia, e não a educação.

- A greve de 35 instituições federais de ensino superior e médio, que já dura mais de 45 dias sem que efetivamente tenha havido negociação concreta para o encaminhamento de soluções, mostra o desinteresse do governo em enfrentar uma questão que se arrasta há anos.
Esse tipo de política vem sendo veementemente denunciado e repudiado pela ANPEd!

- Temos ainda reiteradamente lutado para que a educação não seja tratada como moeda de troca ou objeto de manobras políticas para acomodar interesses político-partidários visando à governabilidade, tal como temos visto acontecer, paradoxal e principalmente, nos últimos tempos.

Para finalizar, conclamamos todos a se envolverem nas discussões que acontecerão nesses próximos três dias, esperando que todos saiam deste evento menos descrentes, mais disponíveis para continuar nossos estudos, nossas pesquisas e nossas lutas. Não é dado a educador algum ceder ao cinismo diante do quadro políticoinstitucional no qual o país está mergulhado! Não nos é dado desesperançar! Ao contrário, nossa tarefa é seguir construindo o sistema nacional de pós-graduação e pesquisa em educação até atingirmos os níveis de qualidade desejados e necessários para todo o sistema educacional brasileiro. Este é o desafio! Esta é a utopia!

BETANIA LEITE RAMALHO, doutora em ciências da educação pela Universidade Autônoma de Barcelona, na Espanha, é professora adjunta no Departamento de Educação da Universidade Federal do Rio Grande do Norte (UFRN). Foi presidente da ANPEd no biênio 2004-2005. Últimas publicações: em co-autoria com Isauro Beltrán Nuñez (UFRN) e Clermont Gauthier (Universidade Laval e CRIFPE/Quebec/Canadá), Formar o professor. Profissionalizar o ensino: perspectivas e desafios (Porto Alegre: Sulina, 1. ed. 2003, 2. ed. 2004); organizado com Isauro Beltrán Nuñez, Fundamentos do ensino-aprendizagem das ciências naturais e da matemática: o novo ensino médio (Porto Alegre: Sulina, 2004); em co-autoria com Isauro Beltrán Nuñez, Estudo das necessidades formativas de professores/as do ensino médio (Porto Alegre: Sulina, 2005). No Programa de Pós-Graduação em Educação da UFRN, coordena a linha de pesquisa Formação e Profissionalização Docente, com os projetos: "A passagem do ensino médio à universidade"; "O acesso e a inclusão de alunos da rede pública à universidade pública”, e "Representação de professores/as em formação sobre a profissão e a profissionalização do trabalho docente" (em colaboração com Isauro Beltrán Nuñez).E-mail: betania.ramalho@terra.com.br 